\title{
AIR POLLUTION IN DELHI: A REVIEW OF PAST AND CURRENT POLICY APPROACHES
}

\author{
LAURA DE VITO ${ }^{1}$, TIM CHATTERTON ${ }^{1}$, ANIL NAMDEO ${ }^{2}$, SHIVA NAGENDRA ${ }^{4}$, SUNIL GULIA $^{5}$, \\ SANJIV GOYAL ${ }^{5}$, MARGARET BELL ${ }^{2}$, PAUL GOODMAN ${ }^{2}$, JAMES LONGHURST $^{1}$, ENDA HAYES $^{1}$, \\ RAKESH KUMAR ${ }^{5}$, VIRENDRA SETHI ${ }^{3}$, SENGUPTA B. GITAKRISHNAN RAMADURAI ${ }^{4}$, \\ SHOBAN MAJUMDER ${ }^{4}$, JYOTHI S MENON ${ }^{4}$, MALLIKARJUN NGAPPA TURAMARI $^{4} \&$ JO BARNES $^{1}$ \\ ${ }^{1}$ Air Quality Management Resource Centre, University of the West of England, UK \\ ${ }^{2}$ Newcastle University, UK \\ ${ }^{3}$ Indian Institute of Technology Bombay, India \\ ${ }^{4}$ Indian Institute of Technology Madras, India \\ ${ }^{5}$ NEERI, India
}

\begin{abstract}
Delhi National Capital Region (Delhi NCR) is facing serious challenges linked to worrying levels of air pollution (mainly $\mathrm{NO}_{2}, \mathrm{PM}_{10}$ and $\mathrm{PM}_{2.5}$ ). The CADTIME prject (Clean Air in Delhi through Implementation, Mitigation and Engagement) aims to understand what is required to deliver significant reductions in levels of air pollution. This paper presents the results of the first stage of the project: it firstly contextualises the challenges of air quality management in Delhi within the broader evolution of environmental policies and governance in India, with particular consideration to the tensions between environmental protection and the country's development objectives. Secondly, it sets out how CADTIME will combine multiple source qualitative and quantitative data to develop an air quality action plan and an implementation strategy. In particular, through two workshops with local and national experts and stakeholders, and two rounds of focus groups with citizens of Delhi we will contrast stakeholders' priorities and preferences for existing and potential solutions to air pollution with citizens' lived experiences, thus assessing the political/technical feasibility and public acceptability of current and proposed measures. Furthermore, we will complement the primary qualitative data with a critical review examining the successes and failures of UK and European policies to draw lessons that can be relevant for Delhi and to avoid ineffective policies and achieve cost-effective solutions for the city in the shortest possible time.
\end{abstract}

Keywords: air quality management, Delhi, mitigation strategy, interventions, public engagement.

\section{INTRODUCTION}

The World Health Organisation (WHO) has recognised ambient air pollution as a class one carcinogen and the fourth highest risk factor for premature death worldwide [1]. In Asia, the situation is exacerbated by rapid urbanisation, industrialisation, and deficiencies in supporting infrastructure. Already in 2010 the Clean Air Initiative for Asian Cities [2] indicated that $58 \%$ of Asian cities (out of 230 ) had annual $\mathrm{PM}_{10}$ concentrations exceeding the WHO annual mean interim target- 1 of $70 \mu \mathrm{g} / \mathrm{m}^{3}$ for $\mathrm{PM}_{10}$ and, moreover, Amann et al. [3] report that $40 \%$ of cities with the highest concentrations of $\mathrm{PM}_{2.5}$ are in India. Previous studies across India have shown strong correlations between respiratory problems, mortality rate, premature death, and air pollution levels [4], [5]. Addressing this problem is now paramount.

In India, air quality is monitored at more than 450 stations across the country by the Central Pollution Control Board (CPCB) under the National Ambient Air Quality Monitoring Programme (NAMP) to assess concentrations at industrial, residential, traffic and ecologically sensitive areas.

The main objective of this monitoring network is to check whether national ambient air quality standards (NAAQS) are being met. If an area fails to meet the NAAQS, then it is classified as non-attainment area where adverse health effects are expected. According to the CPCB, between 2011 and 2015, 94 cities across 22 states registered non-attainment areas. 
The increasing number of cities not attaining the NAAQS puts into question both the adequacy of past and current interventions and the effectiveness of their implementation. Delhi, the national capital of India, is one of the cities with non-attainment areas. Here, extreme air pollution events particularly during the winter months are becoming routine and national and international media outlets have been using expressions such as "Delhi Airpocalypse" or "Death by breath" to describe the scale of the issue [6], [7]. While these extreme, relatively short-term episodes attract the attention of the media worldwide and bring about new emergency measures, it must be stressed that air quality in Delhi is poor all year round. Therefore, an ex-post, reactive set of actions within what can be considered to be a piecemeal legislative framework, is not enough to reduce the impact on public health and the environment in the medium and longer term.

Indeed, many problems remain to be addressed. More needs to be done on the regulation of industrial sources. Furthermore, so far little has been done to formally control domestic emissions in Delhi and improvements have largely been made due to a shift towards the use of (initially bottled, now, in many areas, piped) liquefied petroleum gas (LPG) [8].

The lack of provision of efficient municipal services leads to two primary problems, the open burning of waste; and the widespread use of diesel generators in response to frequent (almost daily) power cuts. On the transport front, Gulia et al. reported that, in Delhi, "the number of vehicles has more than doubled from 3.37 million in 2000 to 8.83 million in 2015" [9]. In addition, a significant share of $\mathrm{PM}_{2.5}$ in ambient air in Delhi comes from the neighbouring States of Haryana and Uttar Pradesh, thus suggesting that addressing only the sources generated within Delhi might not be enough to protect public health [3] and a more comprehensive understanding of the impacts of each source and of the activities that generate pollution, as well as the effectiveness of the policies that have been so far adopted is needed.

Moreover, tackling the challenge of air pollution in Delhi requires a joined-up approach which integrates different perspectives and which considers this issue in relation to other dimensions, such as political changes, economic development, and Delhi citizens' lived experiences with air pollution. This paper illustrates how the Atmospheric Pollution and Human Health (APHH) programme, and within this specifically the CADTIME project are contributing to creating a better and more joined-up knowledge of the issue and potential solutions. Further, the paper presents the preliminary results of the first stage of the CADTIME project, which aims to develop this understanding.

\section{ATMOSPHERIC POLLUTION AND HUMAN HEALTH: THE CONTRIBUTION OF THE CADTIME PROJECT}

To support research on the sources, impacts and potential interventions to mitigate air pollution in Delhi, a programme of projects (Atmospheric Pollution and Human Health, APHH) has been funded by NERC, the Indian Medical Research Council, the NewtonBhabha Fund, and the Indian Ministry of Earth Sciences. The programme is organised into four interrelated themes: validation of sources and emissions of urban air pollution; understanding the underlying chemical and physical processes; impacts of air pollution on health outcomes; investigating mitigation and interventions. Five individual projects will cover the four themes in an integrated way. One of these projects, Clean Air in Delhi through Implementation, Mitigation and Engagement (CADTIME) aims to understand what is required to deliver significant reductions in levels of air pollution, through affordable, effective interventions that consider and respond to future changes, thus dealing primarily with the fourth theme of the APHH programme.

First, the project will help to create a more robust knowledge of the spatial and temporal changes in source emissions, contributing to ambient concentrations and the consequential 
population exposures. This stage will also include the definition of a baseline knowledge of past and current air quality policies. Secondly, CADTIME will identify a set of measures to be implemented in Delhi to achieve the requisite emission reductions for current and two future time horizons (2030) and (2050). Fig. 1 presents an overview of the stages of the project.

Fig. 1 also illustrates CADTIME's methodology which employs a full mixed-methods research design, spanning across methods (quantative and qualitative) and across disciplines (social sciences, physical sciences, engineering). Each stage of data gathering and analysis (both quantitative and qualitative) feeds into the other elements of the project and contributes towards the definition of an integrated Action Plan.

The starting point of the project is to conduct a policy review to develop a deeper understanding of past and current air pollution problems and issues faced when implementing long-term or short-term solutions. This paper presents the preliminary results of this stage (Box 1 in Fig. 1) through a historical lens of environmental and air quality policy in India.

The policy review was conducted based on a combination of primary and secondary sources. Primary sources included: legislative acts (constitutional level, national and local level) court cases and Supreme Court's decisions. Secondary sources included academic literature, Government's agencies' and non-departmental groups reports' and documentation, interest groups' reports and position papers. The data was then analysed thematically; each theme was identified based on its role in shaping air quality policy in India, and will be explored in the following section.

The results of this policy review will inform and underpin the analysis and the interpretation of the primary qualitative data that will be gathered by the CADTIME project team. The policy review will also constitute the basis for generating a deeper understanding of how different and contrasting priorities and perspectives on this issue may be reconciled and translated into sectoral environmental policy, an aspect that will be incorporated in the final Action Plan. The paper then concludes by illustrating the next steps.

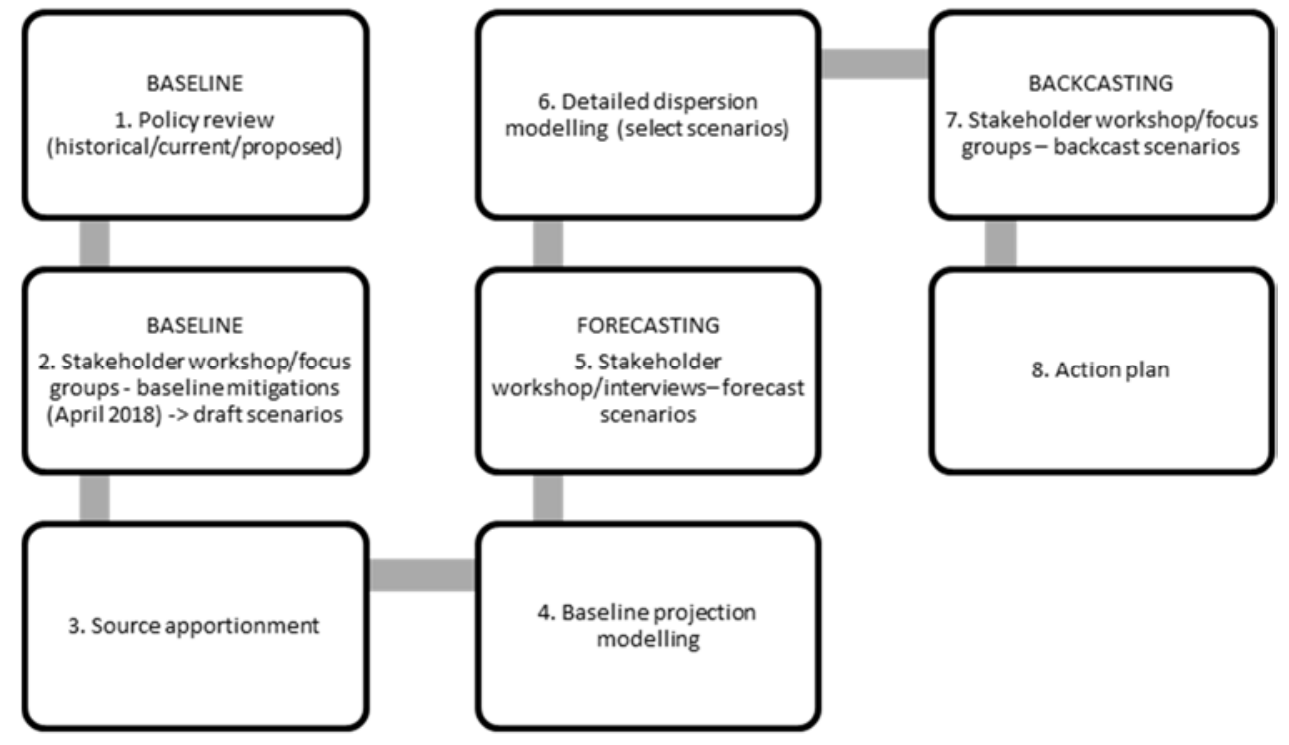

Figure 1: CADTIME: an overview. (Source: authors.) 


\section{ENVIRONMENTAL PROTECTION IN INDIA}

The aim of the policy review is to contextualise air quality interventions in Delhi within the broader evolution of environmental policies and politics in India pointing to the key challenges, exploring long-standing issues and identifying knowledge and policy gaps. In so doing, it highlights the historical tensions linked to the complex relationship between environmental protection and economic development. The aim of the policy review is therefore to create a baseline knowledge in order to explore the best possible options for solutions. The evolution of air quality management in India should be read in the context of larger issues of environmental protection and of the Indian constitutional and political framework. Significant improvements in the levels of atmospheric pollution arguably cannot be achieved by if we look at this issue in isolation from the broader context and if we ignore the interaction of complex and multiple factors that influence pollution sources and affect the development and the implementation of policies.

This section explores the themes resulted from the poicy review, including issues of development, governance and enforcement of environmental, and more specifically air quality policies in India in the 70 years since gaining independence in 1947.

\subsection{Environment and development: a close but complex relationship}

While environmental protection was an important part of societies in ancient India, the beginning of modern environmental protection conventionally dates back to 1972, when the then Prime Minister Indira Gandhi participated in the United Nations Conference on the Human Environment in Stockholm. The UN conference represented a turning point for Indira Gandhi's approach to environmental protection [10]. Indeed, while previously her focus had been primarily on wildlife protection, here she addressed for the first time broader environmental issues and their relationship with developed countries' historical responsibilities, economic growth and development. In her speech she stated:

"Are not poverty and need the greatest pollutants? How can we speak to those who live in villages and slums about keeping the oceans, the rivers and the air clean when their own lives are contaminated at the source?"

And, moreover:

"The environmental problems of the industrialised countries are the result of earlier exploitation as well as of present affluence while those of the developing countries are primarily determined by the manner in which machines are used or abused. In the poorer societies these problems are essentially those of inadequate development and of continuing poverty, unsafe drinking water, malnutrition, poor sanitation, inadequate housing and disease..."

The speech embodies the frame for India's approach to environmental policy to date, an approach that aims to consider development and environment as closely linked and both important pillars for the country. In reality, the balance between environment and development has been variable over time. In fact, following Chopra's [11] classification, we can identify the periods of change in the focus of the Indian Government:

- 1950s-1980s: development constitutes the main core of Government's action while the environment features 'as overarching statement' 
- 1980s: economic growth remains a priority, but environmental concerns rise at government level thus leading to a proliferation of environmental acts and legislation (albeit piecemeal legislation)

- 1990s-2000s: following the Rio Summit on sustainable development, the attention of the Indian government turns to the potential synergies between environmental policy and development; the Indian government reflects on how to integrate environmental sustainability in economic growth and on how to improve public participation in environmental decision-making.

This classification mirrors the development of environmental policymaking, with periods of proliferation of environmental sectoral policies, as the next section shows.

\subsection{Environmental protection in India's Constitutions}

Following Indira Gandhi's participation in the Stockholm conference in 1972, the Indian constitution was amended to include environmental protection. In particular, Art. 48a stipulates that:

The state shall endeavour to protect and improve the environment and to safeguard the forests and wild life of the country

Moreover art. 51(g), Part IV - Fundamental duties - stipulates that:

It shall be the duty of every citizen of India to protect and improve the natural environment including forests, lakes, rivers and wild life and to have compassion for living creatures.

Therefore, environmental protection not only gained constitutional status by theState, but it is also a fundamental right and duty of every citizen.

These two articles become even more poignant if read in conjunction with art. 21, which affirms the right to life:

No person shall be deprived of his life or personal liberty except according to procedure established by law

This link between environmental protection and the right to life was substantiated throughout the years by the Supreme Court. Indeed, in key court cases, (for example but not exclusively in the M.C. Mehta v. Union of India, Damodhar Rao v. Municipal Corporation and Subhash Kumar v. State of Bihar ) the interpretation of the Indian Constitution that sees life - and therefore, public health - as dependent on a healthy and pollution-free environment is made explicit by the Supreme Court.

The Constitutional framework sets out the competences between the federal level and the states. In particular, issues are divided into three lists: the Union list; the State List and the Common or Concurrent List. The environment is not explicitly assigned to any list, but many aspects that are relevant for environmental protections are covered by different governmental tiers. For instance, the Union List includes industries, oil fields and mineral oil resources, fishing beyond territorial waters, regulation of inter-State rivers and river valleys; the State List include aspects related to public health and sanitation such as agriculture, land, fisheries, mines, etc.; in the Common or Concurrent List aspects related to forests, protection of wild 
animals and birds and economic and social planning are included. In addition, also Panchayats and Municipalities are assigned competences with an environmental focus. While a comprehensive review of the structure of environmental governance in India is beyond the scope of this contribution, the allocation of competences between different governmental tiers represents one of the main challenges for Indian policymakers [13], and consequently for the implementation and the enforcement of environmental policies.

\subsection{Developing a mitigation strategy for air pollution}

Since the Stockholm Conference in 1972 and in light of the principles outlined in the Constitution, key pieces of environmental legislation were adopted, including the Water Act (1974); the Air Pollution Act (1981); the Environment Act (1986), Environmental Pollution Control Authority of Delhi NCR (1998), the National Environment Policy (2006), which represented the first strategic initiative for environmental protection aimed at integrating environmental protection with economic and social development, and that explicitly considered issues of inter-generational and intra-generational equity [13], EPCA and, more recently, the National Green Tribunal (2010)

The 1981 Air Pollution Act:

- $\quad$ Stated that the central and state pollution control boards (CPCP and SPCPs) created under the Water Act would carry out the functions of the boards envisaged under the Air Pollution Act;

- Established Air Pollution Control Zones;

- Included noise within the definition of air pollution and included control of pollution caused by motor vehicles;

- Provided that the state government can declare air pollution control areas within the state;

- Declared that the state government can prohibit the use of any fuel other than approved fuel in the area.

The State-level Pollution Control Boards (SPCBs) are responsible for the implementation of the legislation relating to prevention and control of pollution and provides advice to the Governments of Union Territories. Moreover, the CPCB, among other things, advises the Central Government and can execute nationwide programs for the prevention, control or abatement of water and air pollution.

Similar to the EU Ambient Air Quality Directive (2008/50/EC) standards, the Indian National Ambient Air Quality Standards (NAAQS) indicate the average concentration limits for each pollutant in industrial, residential, rural areas and in ecologically sensitive areas.

\subsection{Issues with policy enforcement}

The increasing attention to environmental concerns and pollution over time at all levels of Indian government is in sharp contrast to the evidence of persistently high levels of air pollution. According to some commentators, one reason is that legislative acts are, although comprehensive, piecemeal and reactive and there have been problems with their effectiveness. In particular, it has been claimed that

Central and state governments and the CPCB and SPCBs have adopted a soft attitude towards polluting industries and have done little more than issue warnings. The result is 


\section{that these laws are practised more in violation than conformity and a large number of industries operate without proper safety and pollution control measures [14]}

While the government have been seen to be reactive rather than proactive, the Judiciary System and especially the Supreme Court have played a catalyst role for policymaking and policy implementation on environmental issues. Since 2010 the role of the Supreme Court in driving environmental issues has been curtailed by the creation of the National Green Tribunal; nonetheless, historically, it had a pivotal role in shaping Indian environmental policies.

The Supreme Court drew specific environmental principles upon interpretation of the Constitution, including the precautionary principle, the polluter-pays principle, and the absolute liability principle. On air quality, there have been significant interventions. For example, at the beginning of 1995, it issued orders for the closure or relocation of industrial outfits in Delhi on public health grounds. In another famous landmark decision, the Metha vs. Union of India (1998), the Supreme Court issued suo moto in responding to citizens' concerns over Delhi's pollution levels [15], an order mandating the conversion of the entire Delhi public transprot fleet (DTC) be converted to compressed natural gas (CNG) by April 2001.

It would be easy to assume that the Supreme Court has been acting in the best interest of the environment, and indeed, for a long time the mainstream trend in academia was to consider the Supreme Court unambiguously as a driver for environmental protection. However, more recently and following the later jurisprudence since the early 2000s, this assumption has been critically reviewed and new perspectives have been put forward (see for an overview Sahu, 2014).

First, Dam and Tewary [16] argued that the "environmental activism" of the Court has created a situation of institutional imbalance wherby the judiciary power has been exerting executive power, a situation which has also undermined citizens' ability to engage with the other institutions of the State.

Secondly, the environmental gains won by the courts often brought about cost to individuals. For example, in analysing the Supreme Court directives that led to the closure of industrial outfits in Delhi on public health grounds, Baviskar et al. [17] strongly questioned the Supreme Court's green credentials and pointed out that 'environmental benefits - clean air and water - were obtained at the cost of losing working environments, resources that sustained some of the most vulnerable citizens of Delhi' (see on this also Yearley, 2011, pp. $256-257$ [18]).

These observations raise important environmental justice concerns and, indeed, the bone of the contention seems to bring us straight back to the tension between environment and development; to put it bluntly, has the Supreme Court advanced environmental protection only insofar as it reflected middle-class concerns? It seems that, methodologically, a reading of individual decisions would not contribute to reconciling the different sides of the debate. Rather, we should consider the historical, political and social context and further explore Sahu's argument that the Supreme Court's decisions show different levels of "greenness" because it reflects the changing environmental discourse in India [19]. Doing so will allow us to draw parallels between the Supreme Court's orientation and Chopra's classification of the changing historical balance between environmental concerns and development, and use this classification as a framework to interpret decisions that had an impact on air pollution and on air pollution policies. 


\subsection{Relying on short-term measures: the Delhi Graded Response Action Plan (GRAP)}

The introduction of the NAAQS, and even longer-term measures, such as the introduction of compulsory $\mathrm{CNG}$ or the relocation of industrial estates, did not lead to significant improvements in air quality, which particularly in the main cities has become a public health emergency [20].

In order to address short-term episodes, in November 2016 the Supreme Court instructed the government to produce and implement a Graded Response Action Plan (GRAP) to limit the cases of severe pollution in Delhi National Capital Region (NCR). In January 2017 the GRAP was notified by the Union environment ministry. The GRAP includes a set of reactive and increasingly tougher measures based on the level of air pollution in the city. The actions suggested for each level are cumulative and add up to the level of emergency.

The implementation of measures is complicated by the fact that multiple actors are involved in the process and have different responsibilities. Table 1 includes some of the measures to be taken by different authorities or agencies in case of Severe or Severe+ category.

The measures to be undertaken under "severe" air pollution conditions were implemented in November 2017. To date, the efficacy of each of the enforced actions remains unclear. Moreover, while these actions might prove to be helpful to address critical episodes of high pollution concentrations, these actions fall short of representing a comprehensive, long-term mitigation strategy for Delhi, which addresses also the issue of year-round exceedences of the annual means and which would also require more efforts of cooperation between multiple authorities, and even multiple states.

Further, the assessment of the EPCA [21] suggested that GRAP was too slow, if not ineffective, to fight the air pollution crisis experienced in Delhi at the end of 2017. Major implementation issues emerged and, in addition, also the adequacy of the proposed measures against the scale of the challenge can be put into question. The next section presents the next steps of the CADTIME project and explains how, through a mixed-methods research design, it will contribute to identify future affordable, adequate and effective policies which will incorporate stakeholders' and citizens' insights and experiences, thus making these policies more easily implementable.

\section{CONCLUDING REMARKS AND NEXT STEPS}

This policy review revealed that much more still needs to be done to address the issue of air pollution in Delhi, and that gaps in the policy and social knowledge remain to be explored. In this regard, future research should tackle the key issue of how to identify proactive, affordable, sustainable and effective measures that integrate and solve environmental justice issues as suggested in this policy review. The next steps for CADTIME will involve building on the results presented here as a starting point to creating the Baseline knowledge (as illustrated in Fig. 1).

The Baseline will also integrate primary qualitative data gathered in Delhi through focus groups with citizens, a stakeholder workshop and semi-structured interviews with experts and officers. This will allow not only to gather first-hand insights into real-life policymaking, but also to contrast experts' views with citizens' lived experiences, thus contributing to the academic understanding of the problem.

Subsequently, through a DELPHI-like approach, key stakeholders and citizens will be engaged to provide context and detail on what a clean air future for Delhi would look like, and insights into how we could get there. 
Table 1: Example of responsible authorities and measures to be adopted in case of Sever or Severe+ category. (Source: GRAP.)

\begin{tabular}{|c|c|}
\hline Responsible authorities & Measures \\
\hline $\begin{array}{l}\text { Delhi Pollution Control Committee } \\
\text { (DPCC) }\end{array}$ & $\begin{array}{ll}\text { - } & \text { Stop construction activities } \\
\text { - } & \text { Shut down Badarpur power plant } \\
\text { - } & \text { Stop use of diesel generator sets } \\
\text { - } & \text { Issue advisories in newspapers/ } \\
\text { TV/Radio }\end{array}$ \\
\hline Transport Department & $\begin{array}{ll}\text { - } & \text { Introduce odd and even number plate } \\
\text { - } & \text { Echeme } \\
\text { - } & \text { Increase bus and metro services } \\
\text { - } & \text { Heavy fine for polluting vehicles } \\
\end{array}$ \\
\hline Traffic Police/Delhi Police & $\begin{array}{ll}\text { - } & \text { Stop entry of non-destined trucks } \\
\text { - } & \text { Enforce dust control at construction sites } \\
\text { - } & \text { Enforce ban on firecrackers }\end{array}$ \\
\hline Municipal corporations & $\begin{array}{ll}\text { - } & \text { Stop construction activities; } \\
\text { - } & \text { Enhance parking fees by 3-4 times; } \\
\text { - } & \text { Stop trucks (except essential } \\
& \text { commodities) } \\
\text { - } & \text { Stop garbage burning } \\
\text { - } & \text { Sweep roads mechanically } \\
\end{array}$ \\
\hline $\begin{array}{l}\text { Delhi Public Works } \\
\text { Department/Central PWD/National } \\
\text { Highways Authority }\end{array}$ & $\begin{array}{l}\text { - Increase frequency of mechanised road } \\
\text { sweeping and sprinkling of water on } \\
\text { roads }\end{array}$ \\
\hline Uttar Pradesh & - $\quad$ Regular inspection of polluting units \\
\hline Haryana & $\begin{array}{ll}\text { - } & \text { Farmers encouraged to refrain from } \\
\text { stubble burning } \\
\text { - } & \text { Higher parking fees } \\
\text { - } & \text { Crackdown on garbage burning } \\
\text { - } & \text { Stop brick kilns }\end{array}$ \\
\hline
\end{tabular}

The research will explore the future options for city development and will use city stakeholders (e.g. government departments and agencies with responsibility for the main sources of air pollution associated with waste, transport, construction and energy; government departments and agencies with responsibility for public health; business representatives of the waste, transport, construction and energy sectors) as well as representatives from educational establishments, community groups and members of the public, and wider experts on air quality in Asian cities (through the CADTIME Scientific Advisory Board) to create future scenario options for 2030 and 2050 (Forecasting).

The results of the future-scoping workshop, will be used as the foundation for a subsequent round of workshops and focus groups to develop an open multi-stakeholder dialogue around clean air options for Delhi (Backcasting). Participants will be asked to backcast from the future options, mapping steps back from 2050 to the present to determine what will need to be achieved, and by when, to reach the future options. This trajectory will 
then be used to identify specific emission constraints and other key actions that will need to be taken.

Finally, a Stakeholder Dialogue Workshop with relevant policymakers will be held to explore the variety of pathways chosen and to examine and "crowd-source" a publically acceptable consensus for a clean air pathway in the medium- and long-term to 2050. Workshop participants will undertake a more focused backcasting activity to identify specific emission constraints and other factors that influence the "collective" future pathway. On this basis, and drawing on the identified emissions reductions required under CADTIME, an Integrated Action Plan of measures will be developed including timescales for deploying the interventions and schedules of the responsible parties who need to be involved. Learning from the experiences of UK air quality management, it is intended that the Action Plan will comprise an integrated set of measures at different scales of governance that are interlinked, supportive and complementary. Wherever possible, clear quantitative milestones, based on backcasting-identified targets, will be set for measures in order to assess their effectiveness in reducing air pollutants and public exposure.

Moreover, the qualitative data gathering process will also need to focus on identifying conflicting priorities and common grounds between different stakeholders and decision makers, while, on the other hand contrast them with citizens' lived experiences. In this regard, an investigation into the role of the environmental movement in Delhi, but more broadly in India, could provide new insights into the formulation and implementation of air quality policies so far and into the extent to which civil society, and more broadly the public has been involved in the process.

\section{ACKNOWLEDGEMENTS}

This work was commissioned and funded by NERC, the Medical Research Council, The Ministry of Earth Sciences (Government of India), the Newton-Bhabha Fund, The Department of Biotechnology, Ministry of Science and Technology (Government of India) funding NE/P016588/1

\section{REFERENCES}

[1] WHO, Ambient (Outdoor) Pollution and Health, 2016. http://www.who.int/ mediacentre/factsheets/fs313/en/.

[2] Clean Air Initiative for Asian Cities (CAI-ASIA) Centre. Air Quality in Asia: Status and Trends - 2010 Edition. Pasig City, Philippines, 2010. cleanairasia.org/wpcontent/uploads/portal/files/documents/AQ_in_Asia.pdf .

[3] Amann, M. et al., Managing future air quality in megacities: A case study for Delhi. Atmos. Environ., 161, pp. 99-111, 2017. https://doi.org/10.1016/j.atmosenv. 2017.04.041.

[4] Lahiri, T., Ray, M.R. \& Lahiri, P., Health effects of air pollution in Delhi. Report submitted to Central Pollution Control Board, Delhi, 2006.

[5] Lahiri, T. \& Ray, M.R., Assessment of air pollution related respiratory problem in children of Delhi. Report submitted to Central Pollution Control Board Delhi, 2006.

[6] Indian Express Death By Breath: A look at key studies on Delhi's pollution and how warnings were ignored, 2016. http://indianexpress.com/article/cities/ delhi/death-by-breath-delhi-pollution/. Accessed on: 16 Mar. 2018.

[7] Times of India Airpocalypse again: Air pollution woes return to NCR, authorities are caught napping once more, 2017. https://blogs.timesofindia.indiatimes.com/toieditorials/airpocalypse-again-air-pollution-woes-return-to-ncr-authorities-are-caughtnapping-once-more/. Accessed on: 16 Mar. 2018. 
[8] Chatterton, T.J., Supporting air quality management in Delhi. Environmental Scientist, 20(1), pp. 28-31, 2011.

[9] Gulia, S., Nagendra, S.M.S., Barnes, J. \& Khare, M., Urban local air quality management framework for non-attainment areas in Indian cities. Sci. Total Environ., pp. 619-620, pp. 1308-1318, 2018. https://doi.org/10.1016/j.scitotenv.2017.11.123.

[10] Ramesh, J., Indira Gandhi - A Life in Nature, Simon \& Schuster: London, 2017.

[11] Chopra, K., Development and Environmental Policy in India, Springer: Singapore, 2017.

[12] Damodaran, The Challenge of Multilevel Envrinmental Policy in India. Periodica Oeconomica, pp. 29-37, 2012. http://gti.ektf.hu/anyagok/po/2012/PO2012_ Damodaran.pdf.

[13] Jörgensen, K., Mishra, A. \& Sarangi, G.K., Multi-level climate governance in India: the role of the states in climate action planning and renewable energies. J. Integr. Environ. Sci., 12, pp. 267-283, 2015. https://doi.org/10.1080/1943815X. 2015.1093507.

[14] Curmally, A., Environmental governance and regulation in India. India Infrastructure Report-2002: Governance Issues for Commercialisation, ed. S Morris, Oxford University Press: New Dehli, 2002.

[15] Sebastian \& Thangiah, Compressed natural gas in India: Contemporizing the Delhi pollution case. Universal Journal of Environmental Research and Technology, 3(3), pp. 393-400, 2013.

[16] Dam, S. \& Tewary, V., Polluting environment, polluting constitution: is a "Polluted" Constitution worse than a Polluted Environment? Journal of Environmental Law, 17(1),(3), pp 383-393, 2005.

[17] Baviskar, A., Sinha, S. \& Philip, K., Rethinking Environmentalism: Industrial Pollution in Delhi and Fisheries in Kerala'. Forging Environmentalism; Justice, Livelihood and Constesd Movements, ed. J. Bauer, Sharpe Publications: New York, 2006.

[18] Yearley, S., Citizen Engagement with the Politics of Air Quality: Lessons for Social Theory, Science Studies, and Environmental Sociology. Governing the Air, eds Lidskog and Sundqvist, The MIT Press: London, 2011.

[19] Sahu, Environmental jurisprudence and the Supreme Court. Litigation, Interpretation, Implementation, Orient BlackSwanL Himayatnagar, 2014.

[20] Greenstone, M. \& Hanna, R., Environmental regulations, air and water pollution and infant mortality in India. American Economic Review, 104(10), pp. 3038-3072, 2013.

[21] EPCA, Report on Air pollution in the matter of Writ Petition (C) No 13029 of 1985; M.C Metha v/s UOI \& others, 2017. http://www.epca.org.in/EPCA-Report_77.pdf.

[22] Dwivedi, O.P., India's Environmental Policies, Programmes and Stewardship, MacMillan Press Ltd.: London, 1997.

[23] Priyadarsini, I., Environmental Policies in India towards achieving sustainable development. Journal of Huanities and Social Sciences, 21(1), pp 56-60, 2016.

[24] Leelakrishnan, P., Enviornmental Law in India, 4th ed., LexisNexis: Haryana, 2016.

[25] Tiwari, G., Transport and land use policies in Delhi. Bulletin of the World Health Organisation, 81(6), 2003.

[26] Weidner, H. \& Janicke, M. (eds), Capacity Building in National Environmental Policy: A Comparative Study of 17 Countries, Springer: Berlin, 2002. 